\title{
BMJ Global Health Progressive realisation of universal access to oral health services: what evidence is needed?
}

\author{
Voramon Agrasuta, ${ }^{1}$ Thanasak Thumbuntu, ${ }^{2}$ Raksanan Karawekpanyawong, ${ }^{3,4}$ \\ Warisa Panichkriangkrai, ${ }^{5}$ Shaheda Viriyathorn, ${ }^{5}$ Tanapon Reeponmaha, ${ }^{6}$ \\ Wararat Jaichuen, ${ }^{5,7}$ Woranan Witthayapipopsakul, ${ }^{5}$ Piyada Gaewkhiew, ${ }^{4}$ \\ Piyada Prasertsom, ${ }^{1}$ Viroj Tangcharoensathien ${ }^{5}$
}

To cite: Agrasuta V, Thumbuntu T, Karawekpanyawong $\mathrm{R}$, et al. Progressive realisation of universal access to oral health services: what evidence is needed?BMJ Global Health 2021;6:e006556. doi:10.1136/ bmjgh-2021-006556

Handling editor Seye Abimbola

Received 8 June 2021

Accepted 29 June 2021

Check for updates

C Author(s) (or their employer(s)) 2021. Re-use permitted under CC BY-NC. No commercial re-use. See rights and permissions. Published by BMJ.

For numbered affiliations see end of article.

Correspondence to Voramon Agrasuta;

voramon.a@anamai.mail.go.th
In May 2021, the 74th World Health Assembly adopted a resolution on oral health, ${ }^{1} 14$ years after its last resolution on oral health (WHA60.17) in 2007, ${ }^{2}$ with slow progress on access to oral health services. The lack of global-level indicators for oral health monitoring is one of the major deficiencies in driving national and global universal health coverage (UHC) agendas on oral health.

Prevalence of untreated oral diseases has increased over the last two decades, ${ }^{3}$ and the global prevalence rate of oral disorders was ranked first among all diseases since 1990. The rate increased from 43634 cases per 100000 population in 1990 to 45035 cases per 100000 population in $2019 .^{4}$

Oral health services are expensive ${ }^{5}$ and usually not included in ${ }^{6}$ or are only partially covered by UHC benefit packages. ${ }^{7}$ This results in either high levels of out-of-pocket payments or high incidence of unmet needs, affecting vulnerable populations. For these reasons, private insurance shifts in to cover oral health costs in high-income countries. ${ }^{8}$ Only $35 \%$ of people with oral health problems in low-income countries were able to receive treatment within a year, whereas the rate was as high as $82 \%$ in high-income countries. ${ }^{9}$

Out-of-pocket expenditure for oral health services is a significant drain of the limited household budgets in the most vulnerable and can increase poverty. Even in highincome countries, oral health expenditure accounted for approximately $20 \%$ of out-ofpocket health expenditure. ${ }^{7}$ Furthermore, availability and access to oral health services at a primary care level are inadequate or lacking in low-income and middle-income countries. ${ }^{10}$ Unmet oral health needs are higher than unmet medical needs and there is a large rich-poor gap in unmet oral health
Summary box

Oral disorder has the highest global prevalence rate of all diseases and has been increasing over the past two decades.

- In addition to inadequate service provisions and funding, existing monitoring systems are fragmented, irregular, and lacking indicators for monitoring progress, informing policy and holding policymakers accountable.

- Universal oral health services should be integrated into national universal health coverage agendas.

- To achieve this, countries need to develop and monitor essential indicators in the following domains: population coverage, service provision, access to care and financing.

needs reported by members of the Organization for Economic Co-operation and Development (OECD). ${ }^{11}$

Even though the 2007 World Health Assembly urged countries to incorporate oral health indicators into their national information systems for monitoring progress, ${ }^{2}$ key indicators on universal oral health services have yet to be developed.

We conducted an informal review of existing global oral health data by searching for global oral health surveys and reports on the World Health Organization (WHO) platforms, PubMed, Scopus and Google Scholar. The search terms included 'oral health data' and 'global/world oral health'. We also tried to link the oral health data with the UHC, hence, the search terms related to the UHC dimensions, such as population coverage, service coverage and financial protection were added. Most resources we found were articles, policy documents and meeting notes, which are not global monitoring databases. Despite efforts contributed by all partners, we 
have found that the available data are fragmented, not covering most countries and lacking continuity. Available information and evidence cannot support the driving of the UHC agenda as called for by the 2021 World Health Assembly Resolution. ${ }^{1}$

In 1996, the WHO established the Oral Health Country/Area Profile Programme (CAPP) to monitor oral health status, ${ }^{12}$ supported by Malmö University, Sweden for dental status and information concerning oral health system and Niigata University, Japan for periodontal conditions. ${ }^{13}$ The most updated Decayed/ Missing/Filled Teeth Index for 12-year-old children is from 2017 reported by Malaysia, Sweden and the UK, ${ }^{14}$ while the latest periodontal data reported from Thailand was in 2017, Japan in 2016 and Namibia in 2013. ${ }^{15}$ The Global Health Observatory (GHO), in the section for non-communicable diseases, covers oral health-related common risk factors, for example, diet, use of tobacco and alcohol, ${ }^{16}$ and oral health workforce. ${ }^{17}$

Most data platforms, such as CAPP, ${ }^{14}{ }^{15}$ GHO data repository, ${ }^{17}$ Global Cancer Observatory, ${ }^{18}$ Global Health Expenditure Database ${ }^{19}$ and Health at a Glance, ${ }^{20}$ are regularly published by OECD members but cover insufficient indicators to drive the UHC agenda. Other platforms, such as World Oral Health Report, ${ }^{21}$ World Health Survey 2002-2004, ${ }^{22}$ World Federation of Public Health Associations' Oral Health Working Group ${ }^{23}$ and Oral Health Towards the Year 2030, ${ }^{24}$ are ad hoc and not comprehensive.

Though UHC facilitates access to oral health services and provides financial risk protection, ${ }^{25}$ the inclusion of oral health services into UHC benefit packages needs a courageous political decision. We suggest that all stakeholders, including the population, fully engaged in reaching the consensus. As a prerequisite, the government should expand its health budget to include oral health services. Under the oral health budget, it should prioritise urgent oral treatment, atraumatic restorative treatment, and prevention and promotion interventions for the neediest population who cannot afford to pay or target populations, such as children. ${ }^{6}$ These services are low $\operatorname{cost}^{26}$ and should be affordable for the government. When resources are more favourable, the government may consider expanding the benefit package to more comprehensive services and to cover wider populations. Additionally, if there is a resource gap, co-payment can be considered for advanced and specialised curative services with an exemption for prevention and promotion services and low-income population.

To achieve universal oral health services, we propose four sets of national-level indicators.

First, population coverage by urgent oral treatment, atraumatic restorative treatment, prevention and promotion interventions, and affordable fluoride toothpaste as measured by the number of days of earnings needed to purchase an annual $182.5 \mathrm{~g}$ of the cheapest toothpaste. ${ }^{27}$

Second, service provision as measured by the proportion of primary care which integrates and provides oral health services, promotion and prevention, the number of oral health workforce (including dentists, dental auxiliaries, dental assistants and dental technicians) per 10000 population, and the extent of oral health services in the UHC benefit packages.

Third, access to care as measured by percentages of people who had at least one visit to oral health services during last year, annual incidence of unmet oral health needs and reasons for unmet need.

Fourth, financing oral health services as measured by current health expenditure on oral health services per capita and financial sources such as out-of-pocket payments, governments and donors.

These sets of indicators should be prioritised, with engagement from relevant stakeholders, in line with the country's context and institutional capacity. With political and financial commitments by national health authorities, these indicators will support policy formulation to drive the universal oral health agenda in their countries. Standardising national oral health indicators not only contributes to national use, it also provides global monitoring of progress.

Regular publications of country oral health profiles, similar to the global tuberculosis report, ${ }^{28}$ road safety report ${ }^{29}$ and tobacco report ${ }^{30}$ have shown to be powerful in driving their respective agenda. At the global level, therefore, the WHO should include additional key oral health indicators in the GHO. This would only be feasible if WHO member states establish robust monitoring systems with synchronised national and global indicators.

Despite these relevant recommendations, challenges remain, especially in low-income and middle-income countries since they generally lack regular national surveys to monitor levels of out-of-pocket payment, service utilisation rates, unmet oral health needs ${ }^{31}$ and household's affordability for fluoride toothpaste. The governments must prioritise establishing a monitoring and evaluation system and indicators for oral healthcare with the engagement of the countries' stakeholders. The engagement builds ownership and commitment, which gradually strengthen the monitoring and evaluation system itself. Besides, the WHO and international development partners should support those countries in conducting surveys through funding or mentoring.

\section{Author affiliations}

${ }^{1}$ Bureau of Dental Health, Department of Health, Ministry of Public Health, Nonthaburi, Thailand

${ }^{2}$ Royal Thai Army Medical Department, Ministry of Defence, Bangkok, Thailand ${ }^{3}$ Division of Preventive Dentistry, Graduate School of Medical and Dental Sciences \& Faculty of Dentistry, WHO Collaborating Centre for Translation of Oral Health Science, Niigata University, Niigata, Japan

${ }^{4}$ Department of Community Dentistry, WHO Collaborating Centre for Oral Health Education and Research, Faculty of Dentistry, Mahidol University, Bangkok, Thailand

${ }^{5}$ International Health Policy Programme, Ministry of Public Health, Nonthaburi, Thailand

${ }^{6}$ College of Public Health, National Taiwan University, Taipei, Taiwan

${ }^{7}$ Health Administration Division, Office of the Permanent Secretary, Ministry of Public Health, Nonthaburi, Thailand 
Contributors VT-study design and conceptualisation. VA, TT, RK, WP, SV, TR, WJ, WW, PG and PP—reviewing. VA — writing original draft preparation. VT, WP, RK and SV-writing review and editing. VT-supervision. All authors have read and agreed to the published version of the manuscript.

Funding The Global Health Diplomacy Program under WHO-Royal Thai Government (RTG) Country Cooperation Strategy (CCS-GHD) managed by the International Health Policy Program Foundation (IHPF) provides financial support for this work.

Competing interests None declared.

Patient consent for publication Not required

Provenance and peer review Not commissioned; externally peer reviewed.

Data availability statement Data are available in a public, open access repository.

Open access This is an open access article distributed in accordance with the Creative Commons Attribution Non Commercial (CC BY-NC 4.0) license, which permits others to distribute, remix, adapt, build upon this work non-commercially, and license their derivative works on different terms, provided the original work is properly cited, appropriate credit is given, any changes made indicated, and the use is non-commercial. See: http://creativecommons.org/licenses/by-nc/4.0/.

\section{REFERENCES}

1 World Health Organization. World Health Assembly resolution: WHA 74.5 Oral Health, 2021.

2 World Health Organization. World Health Assembly resolution: WHA 60.17 Oral Health: action plan for promotion and integrated disease prevention, 2007.

3 Kassebaum NJ, Bernabé E, Dahiya M, et al. Global burden of untreated caries: a systematic review and metaregression. J Dent Res 2015;94:650-8.

4 The Institute for Health Metrics and Evaluation. Global burden of disease (GBD), 2019. Available: https://vizhub.healthdata.org/gbdcompare/ [Accessed 28 May 2021].

5 Petersen PE. World Health Organization global policy for improvement of oral health-World Health Assembly 2007. Int Dent J 2008;58:115-21.

6 Wang TT, Mathur MR, Schmidt H. Universal health coverage, oral health, equity and personal responsibility. Bull World Health Organ 2020;98:719-21.

7 World Health Organization. Oral health key facts. Available: https:// www.who.int/news-room/fact-sheets/detail/oral-health [Accessed 28 May 2021].

8 Paris V, Devaux M, Wei L. Health systems institutional characteristics: a survey of 29 OECD countries. Paris: Organisation for Economic Co-operation and Development, 2010.

9 Hosseinpoor AR, Itani L, Petersen PE. Socio-economic inequality in oral healthcare coverage. J Dent Res 2012;91:275-81.

10 Mathur MR, Williams DM, Reddy KS, et al. Universal health coverage: a unique policy opportunity for oral health. $J$ Dent Res 2015;94:3S-5S

11 OECD/European Union. Health at a glance: Europe 2020: state of health in the EU cycle. Paris: OECD Publishing, 2020.
12 Petersen PE, Bourgeois D, Bratthall D, et al. Oral health information systems-towards measuring progress in oral health promotion and disease prevention. Bull World Health Organ 2005;83:686-93.

13 Malmö University. Oral Health Country/Area Profile Project: about CAPP. Available: https://capp.mau.se/about-capp/ [Accessed 28 May 2021].

14 Malmö University. Oral Health Country/Area Profile Project: download CAPP data. Available: https://capp.mau.se/download/ [Accessed 28 May 2021].

15 WHO Collaborating Centre for Translation of Oral Health Science, Niigata University. Periodontal Country Profiles. Available: https:// www5.dent.niigata-u.ac.jp/ prevent/perio/perio.html [Accessed 28 May 2021].

16 Sheiham A, Watt RG. The common risk factor approach: a rational basis for promoting oral health. Community Dent Oral Epidemiol 2000;28:399-406.

17 World Health Organization. The global health observatory indicators. Available: https://www.who.int/data/gho/data/indicators [Accessed 28 May 2021].

18 World Health Organization. The Global Cancer Observatory (GCO). Available: https://gco.iarc.fr/[Accessed 28 May 2021].

19 World Health Organization. Global health expenditure database. Available: https://apps.who.int/nha/database/Select/lndicators/en [Accessed 28 May 2021].

20 OECD. Health at a glance 2019: OECD indicators. Paris: OECD Publishing, 2019.

21 World Health Organization. The world oral health report 2003: continuous improvement of oral health in the 21st century-the approach of the WHO Global Oral Health Programme. Switzerland: World Health Organization, 2003.

22 Global Health Data Exchange. World Health Survey (WHS). Available: http://ghdx.healthdata.org/series/world-health-survey-whs [Accessed 28 May 2021].

23 Lomazzi M, Wordley V, Bedi R. Dental public health capacity worldwide: results of a global survey. J Public Health Policy 2016;37:528-42.

24 Petersen PE, Baez RJ, Ogawa H. Global application of oral disease prevention and health promotion as measured 10 years after the 2007 World Health Assembly statement on oral health. Community Dent Oral Epidemiol 2020;48:338-48.

25 Fisher J, Selikowitz H-S, Mathur M, et al. Strengthening oral health for universal health coverage. The Lancet 2018;392:899-901.

26 Frencken JE, Holmgren CJ, van Palenstein Helderman WP. Basic package of oral care (BPOC). Nijmegen, Netherlands: WHO Collaborating Centre for Oral Health Care Planning and Future Scenarios, University of Nijmegen, 2002.

27 Goldman AS, Yee R, Holmgren CJ, et al. Global affordability of fluoride toothpaste. Global Health 2008;4:7.

28 World Health Organization. Tuberculosis profile. Available: https:// worldhealthorg.shinyapps.io/tb_profiles/? inputs_\&entity_type $=\%$ 22country\%22\&lan=\%22EN\%22\&iso2=\%22AF\%22 [Accessed 28 May 2021].

29 World Health Organization. Violence and injury prevention: country profiles. n.d

30 World Health Organization. Global report on trends in prevalence of tobacco use 2000-2025. 3rd edn. Geneva: World Health Organization, 2019.

31 Thammatacharee $\mathrm{N}$, Tisayaticom $\mathrm{K}$, Suphanchaimat $\mathrm{R}$, et al. Prevalence and profiles of unmet healthcare need in Thailand. BMC Public Health 2012;12:923. 